PALABRAS CLAVE

Desarrollo económico

Distribución del ingreso

Empleo

Productividad

Ingresos familiares

Indicadores económicos

Política social

Estrategias del desarrollo

Chile

Ricardo Infante B.

Consultor Internacional

• infanter@mi.cl

Osvaldo Sunkel

Presidente del Consejo Editorial,

Revista CEPAL

• osvaldo.sunkel@cepal.org

REVISTA CEPAL 97 - ABRIL 2009

\section{Chile: hacia un desarrollo inclusivo}

\author{
Ricardo Infante B. y Osvaldo Sunkel
}

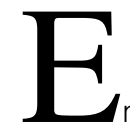

n este trabajo se sugiere que Chile debe adoptar una estrategia de desarrollo renovada de largo plazo que conduzca a un desarrollo inclusivo con equidad creciente, a fin de superar los efectos no deseables del tipo de crecimiento económico vigente, esto es, la persistencia de una inaceptable desigualdad de los ingresos, de los niveles y de la calidad de vida, así como la creciente sensación de exclusión social. Para abordar estos temas, primero se muestra la evolución de la desigualdad en las dos últimas décadas. A continuación, se analizan las características de la estructura productiva de la economía chilena, que se consideran un factor determinante de la desigualdad. A partir de este análisis, se proponen los lineamientos generales de una estrategia renovada que incluya explícitamente los diferentes estratos productivos y sociales del proceso de crecimiento. Finalmente, se señalan las áreas de política que serían clave para lograr un desarrollo inclusivo. 


\section{I}

\section{Introducción}

En los últimos veinte años, Chile ha tenido un sólido crecimiento económico que se ha manifestado en una duplicación del ingreso per cápita y una notable reducción de la pobreza absoluta. Sin embargo, persiste una inaceptable desigualdad de ingresos y de los niveles y calidad de vida, al tiempo que aumenta la percepción de exclusión social. En este trabajo tratará de demostrarse que probablemente estos resultados persistirán en el futuro, a menos que se reflexione sobre las características del tipo de crecimiento económico vigente y se adopte una estrategia de desarrollo renovada de largo plazo conducente a un desarrollo inclusivo con equidad creciente.
En lo que sigue se muestra — con indicadores seleccionados- la evolución de la desigualdad desde comienzos de la década de 1990. Luego se analizan en profundidad las características de la estructura productiva de la economía chilena, que se consideran un factor determinante de la desigualdad al que no se ha dado la debida importancia. A partir de este análisis se proponen los lineamientos generales de una estrategia renovada que incluya explícitamente los diferentes estratos productivos y sociales del proceso de crecimiento. Finalmente, se señalan las áreas de política que se consideran clave para lograr un desarrollo inclusivo.

\section{II}

\section{El crecimiento con desigualdad}

El excepcional crecimiento económico de Chile (5,5\% medio anual) condujo a que su ingreso per cápita se elevara un $96 \%$ entre 1990 y 2007. Junto con la acción decidida y eficaz de las políticas sociales, ello contribuyó a que en ese período la pobreza absoluta se redujera a casi la tercera parte, del 38,6\% al 13,7\% (MIDEPLAN, 2007). Además, entre otros avances, se logró una inserción dinámica en el proceso de globalización y una extraordinaria expansión en materia de infraestructura y servicios públicos, así como en cobertura educacional, vivienda, salud y seguridad social.

Sin embargo, persiste un considerable déficit social. La tasa de desocupación ha seguido siendo elevada (8\%), al igual que la informalidad de los ocupados (38\%). En el período 1990-2006 aumentó la precariedad laboral, los trabajadores asalariados sin contrato se incrementaron del $14,3 \%$ al $17,3 \%$ del total, los que no cotizan en la seguridad social se mantuvieron en torno al $33 \%$, creció la importancia de los contratos de corto plazo y la rotación de los puestos de trabajo continuó siendo elevada.

$\square$ Los autores agradecen los comentarios de H. Assael, S. Molina y O. Muñoz a una versión anterior de este artículo, así como los de un evaluador anónimo del texto.
Además, se deterioró la participación de los trabajadores en el producto, ya que el aumento anual de los salarios reales $(2,9 \%)$ fue inferior al producto interno bruto (PIB) por ocupado $(3,3 \%)$. Todo ello contribuyó a que en Chile se mantuviera prácticamente inalterada la muy desigual distribución personal del ingreso que lo caracteriza: el ingreso autónomo del $20 \%$ más rico de la población supera 13 veces a aquel del $20 \%$ más pobre. Esta relación se reduce a 11,2 si se considera el ingreso monetario y a 6,8 veces si se tiene en cuenta el efecto global de la política social en el ingreso autónomo de los hogares (MIDEPLAN, 2006a).

En estas circunstancias, se considera indispensable introducir el concepto de pobreza relativa, pues esta continúa afectando a casi un tercio de la población. A diferencia del concepto de pobreza absoluta, en el de pobreza relativa se establecen normas sociales y estándares de consumo que varían en la medida en que evoluciona el ingreso medio de las familias. En este contexto, ella se define como el grupo de personas o familias cuyo nivel de ingreso es inferior a 0,6 veces el ingreso medio, constituyéndose en el sector relativamente excluido de la sociedad. De acuerdo con cifras de la Encuesta de Caracterización Socioeconómica Nacional (CASEN) (2006), este sector abarcaría un 
25,6\% de la población, esto es, alrededor de 4,3 millones de personas. ${ }^{1}$

En resumen, el modelo de economía social de mercado prevaleciente, modificado por la estrategia de "crecimiento con equidad" adoptada en 1990 (Muñoz, 2007; Sunkel, 2006a), ha funcionado muy bien para la mayoría de los chilenos, pero no consigue reducir la desigualdad y persisten importantes niveles de pobreza. El Estado, con su acción compensatoria, consiguió disminuirlos en forma significativa, pero queda un remanente considerable que se ha mostrado irreductible (Contreras, 1998; Bravo y Contreras, 1999; Sunkel, 2006b).

De acuerdo con el pensamiento económico dominante, esta deficiencia en el modo de funcionamiento del actual modelo se superaría aumentando la tasa de crecimiento económico y mejorando las políticas sociales. Aunque algo se puede lograr por esa vía, en este trabajo se sostiene que es necesario diseñar una estrategia de desarrollo diferente. El problema de fondo no es tanto la velocidad del crecimiento como su composición, o sea, las profundas diferencias de productividad y calidad de la estructura productiva, tanto de los sectores productores de bienes como de los servicios.

Como se muestra detalladamente en la sección siguiente, en el segmento moderno, competitivo y de elevada productividad — como es el caso del orientado al comercio exterior- los grupos sociales (minoritarios) vinculados a este y las áreas geográficas pertinentes se expanden dinámicamente, muy por encima del promedio, pero con escasa creación de empleos.

Los segmentos de productividad mediana o baja, que incluyen el grueso del empleo informal y precario, los grupos sociales pertinentes (mayoritarios) y los espacios geográficos en que se localizan, corresponden a actividades de crecimiento lento que tienen escasos vínculos con los sectores de punta. Participan solo en forma tangencial en el crecimiento y, en consecuencia, por más elevado que este sea no genera los resultados esperados para la mediana, pequeña y microempresa y para los sectores sociales de medianos y menores ingresos correspondientes.

\footnotetext{
${ }^{1}$ El criterio utilizado para medir la pobreza relativa se basa en la metodología establecida en EUROSTAT (1998) para definir la noción de exclusión. En el estudio se consideraron los siguientes factores determinantes: ingresos bajos, situación en el mercado de trabajo e indicadores de situación vinculados a la condición de exclusión.
}

Se trata de una dinámica divergente, con efectos socioculturales y políticos contradictorios. Quienes se insertan en el proceso de globalización satisfacen plenamente las expectativas socioculturales y de consumo que este genera; son los ganadores. Los que quedan al margen se ilusionan con el bombardeo televisivo y publicitario de la globalización a nivel virtual, que genera delirantes expectativas de consumo "pagadero en cómodas cuotas mensuales". Se genera así una aguda contradicción entre expectativas y realidad, acentuada por el agobio del endeudamiento creciente a que da lugar no solo la exacerbación del consumo, sino también la privatización de los servicios sociales que ha afectado en especial a los sectores medios. Posiblemente se encuentre aquí una de las causas de la desafección e insatisfacción social crecientes respecto de la democracia, e incluso de conductas antisistémicas tales como las reiteradas protestas violentas, la delincuencia y la drogadicción, que no parecieran tener correspondencia con el exitoso crecimiento económico (Calderón, 2008; Sunkel, 2008).

En este contexto, la acción del Estado está centrada en implementar políticas públicas en favor de los excluidos, sobre todo de los más pobres. Esto ha permitido atenuar las carencias de estos grupos sociales, pero no ha resuelto los problemas de la pobreza relativa y de la equidad, es decir, no se ha logrado disminuir las enormes diferencias entre los grupos sociales excluidos y los de mayores niveles de ingreso.

Como lo revela la experiencia reciente, los efectos sociales de esta dinámica disociadora y divergente pueden en el mejor de los casos atenuarse con tasas más elevadas de crecimiento y una mayor y mejor utilización del gasto social. De ahí que para enfrentar decididamente este problema haya que pensar en cambiar radicalmente el enfoque de las políticas públicas, adoptando una estrategia de desarrollo inclusivo que permita superar gradualmente la heterogeneidad estructural prevaleciente en los diferentes estratos, sectores y regiones de la matriz productiva y social del país, puesto que - como se trata de mostrar en este trabajo- además de la concentración de la riqueza y el mal funcionamiento del mercado de trabajo, ${ }^{2}$ esa diversidad es uno de los principales obstáculos que impiden lograr el crecimiento con equidad y contribuir así a mejorar la convivencia ciudadana y la democracia.

\footnotetext{
${ }^{2}$ En relación con estos temas, véase Solimano y Pollak (2006).
} 


\section{III}

\section{El concepto de heterogeneidad estructural de la CEPAL}

El análisis de la estructura económica de Chile, que se presenta más adelante en este trabajo, rescata el concepto de heterogeneidad estructural formulado originalmente por la Comisión Económica para América Latina y el Caribe (CEPAL) en la década de 1960 (CEPAL, 1964) y desarrollado posteriormente por varios autores (Pinto, 1970; Sunkel, 1971; Pinto y Di Filippo, 1974 y 1982; Sunkel, 1978; Souza y Tokman, 1979; Infante, 1981; Tokman, 1982). Un enfoque similar fue desarrollado también en la misma época para la heterogeneidad productiva en el caso del sector industrial de los países desarrollados (Salter, 1966).

En CEPAL (1964) se postula que en esa época la heterogeneidad estructural de América Latina se manifestaba en los niveles diferentes de productividad de los ocupados en los distintos estratos productivos, lo que caracterizaba el funcionamiento económico de la región y además era el factor originario de la desigual distribución del ingreso. Así, la estructura económica estaba formada por tres estratos con diverso acceso a la tecnología y a los mercados, los que en el decenio de 1960 habrían tenido las siguientes características:

i) Un estrato tradicional cuyos niveles de productividad e ingreso eran ínfimos. Este segmento incluía un $36,4 \%$ de los ocupados y generaba solo un $5,1 \%$ del PIB de la región (véase el cuadro 1). ii) Un estrato moderno, compuesto de actividades de exportación y grandes empresas industriales y de servicios de gran escala operativa, que captaban una fracción determinante del mercado local y cuya productividad por ocupado tenía un nivel similar al promedio de las economías desarrolladas. Absorbía solo un $13,1 \%$ de los ocupados y producía un 53,3\% del PIB.

iii) Un estrato intermedio que correspondía a sectores en que la productividad de los ocupados era similar a la del promedio de los países representaba la mayor parte del empleo $(50,6 \%)$ y generaba una fracción importante del PIB $(41,6 \%)$.

La heterogeneidad del aparato productivo se manifestaba en que el producto por ocupado del estrato moderno superaba cuatro veces el promedio, 29 veces el del estrato tradicional y cerca de cinco veces el intermedio. Estas diferencias de productividad se trasladaban a los ingresos de los ocupados y constituían, por tanto, un factor determinante de la mala distribución del ingreso en América Latina. ${ }^{3}$

\footnotetext{
${ }^{3}$ Véase Cimoli, Primi y Pugno (2006). En cuanto a la relación entre productividad y heterogeneidad estructural, véanse Cimoli (2005) y Rupfer y Rocha (2005).
}

América Latina: producto, empleo y productividad según estratos productivos, década de $\mathbf{1 9 6 0}$

(En dólares y porcentajes)

\begin{tabular}{|c|c|c|c|c|c|c|c|}
\hline \multirow{3}{*}{ Estrato productivo } & \multicolumn{2}{|c|}{ PIB } & \multicolumn{2}{|c|}{ Empleo } & \multicolumn{3}{|c|}{ PIB por ocupado } \\
\hline & \multirow{2}{*}{ Nivel $^{\mathrm{a}}$} & \multirow{2}{*}{ Porcentaje } & \multirow{2}{*}{ Nivel $^{b}$} & \multirow{2}{*}{ Porcentaje } & \multirow{2}{*}{ Nivel $^{c}$} & \multicolumn{2}{|r|}{ Índices } \\
\hline & & & & & & Tradicional $=1$ & Total América Latina $=1$ \\
\hline Moderno & 61,1 & 53,3 & 10,3 & 13,0 & 5,9 & 29,5 & 3,9 \\
\hline Intermedio & 47,7 & 41,6 & 39,9 & 50,6 & 1,2 & 6,0 & 0,8 \\
\hline Tradicional & 5,8 & 5,1 & 28,7 & 36,4 & 0,2 & 1,0 & 0,1 \\
\hline Total & 114,6 & 100,0 & 78,9 & 100,0 & 1,5 & 7,5 & 1,0 \\
\hline
\end{tabular}

Fuente: elaboración propia sobre la base de Z. Slavinsky, "Anexo estadístico", La mano de obra y el desarrollo económico de América Latina en los últimos años (E/CN.12/L.1), Santiago de Chile, Comisión Económica para América Latina y el Caribe (CEPAL), 1964.

\footnotetext{
a Miles de millones de dólares de 1960.

b Millones de trabajadores.

c Miles de dólares de 1960
} 


\section{IV}

\section{La estructura económica de Chile}

A continuación se presenta un análisis basado en los resultados empíricos de un estudio reciente sobre las relaciones entre producción y empleo según estratos productivos (Lagos M., 2008), elaborado con datos de la última matriz de insumo-producto del Banco Central, 2003, y del Servicio de Impuestos Internos de Chile, 2007.

La heterogeneidad de la economía chilena queda de manifiesto al examinar los diferentes niveles de productividad de los diversos estratos de producción, el tipo de relaciones intersectoriales, la generación de valor agregado y la distribución primaria del ingreso, así como la incidencia de cada estrato productivo en la dinámica de la estructura económica. Finalmente, se muestra cómo se ha invertido parcialmente la desigualdad generada por la heterogeneidad productiva mediante una política focalizada de gasto social.

\section{Diferencias de productividad según ramas de actividad y tamaño de la empresa}

Para ilustrar el carácter heterogéneo de la economía chilena se utilizan los datos de producción y empleo según ramas de actividad económica y tamaño de las empresas correspondientes al año $2003 .^{4}$

Los sectores (ramas de actividad económica) se han organizado en tres grupos representativos de tres niveles marcadamente diferentes de productividad: baja, intermedia y alta (véase el cuadro 2). Se incluyen también los datos de productividad de las empresas según si son pequeñas, medianas o grandes, por sectores. ${ }^{5}$ Finalmente, se muestran los índices de productividad según el tamaño de las empresas en cada sector, los que permiten apreciar la heterogeneidad intrasectorial (dentro de cada sector) e intersectorial (entre sectores) de la economía.

Al comparar los niveles de productividad por sectores, se observa que el promedio de la minería es 15 veces superior al registrado en la agricultura, en tanto que el de la construcción y la industria lo duplica y cuadruplica, respectivamente. En cuanto a las diferencias intrasectoriales se aprecia, por ejemplo, que en la agricultura la

\footnotetext{
${ }^{4}$ Para realizar esta estimación se utilizó una matriz de insumo-producto (2003) con nueve sectores, según tamaño de las empresas. Al respecto, véase Lagos M. (2008).

${ }^{5}$ Se aproxima al concepto original de estratos tradicional, intermedio y moderno.
}

productividad de los establecimientos grandes es siete veces superior a la de los pequeños, relación que aumenta a 12 veces en el caso de la construcción y, más aún, a 40 veces en el de la minería. En suma, los datos muestran que las diferencias intrasectoriales de la productividad son significativamente superiores que las intersectoriales.

Por otra parte, las cifras de empleo muestran que las ramas de actividad económica con mayor capacidad de retención de mano de obra de los establecimientos pequeños ${ }^{6}$ (incluye actividades informales y microempresas) son las que tienen menor nivel de productividad en comparación con el resto (véase el cuadro 2 a). Tal es el caso de los sectores de la agricultura, los servicios comunales y el comercio, que contienen entre un $47 \%$ y un $59 \%$ de los ocupados en empresas pequeñas y actividades de baja productividad.

CUADRO 2

Chile: producción por ocupado según sectores $^{a}$ y tamaño de las empresas, 2003

(Índice establecimientos pequeños, agricultura $=100$ )

\begin{tabular}{|c|c|c|c|c|}
\hline \multirow[b]{2}{*}{ Sector } & \multicolumn{4}{|c|}{ Tamaño de la empresa } \\
\hline & Pequeña & Mediana & Grande & $\begin{array}{c}\text { Total } \\
\text { nacional }\end{array}$ \\
\hline \multicolumn{5}{|l|}{ Productividad baja } \\
\hline Agricultura & 100,0 & 114,8 & 718,2 & 100,0 \\
\hline Servicios comunales & 100,0 & 146,6 & 408,4 & 103,5 \\
\hline Comercio & 100,0 & 102,5 & 914,8 & 139,7 \\
\hline \multicolumn{5}{|l|}{ Productividad mediana } \\
\hline Construcción & 100,0 & 246,7 & 1270,5 & 217,7 \\
\hline Transporte-comercio & 100,0 & 435,0 & 1761,1 & 356,8 \\
\hline Manufactura & 100,0 & 262,1 & 2458,9 & 426,2 \\
\hline \multicolumn{5}{|l|}{ Productividad alta } \\
\hline Establecimientos financieros & - & - & - & 636,0 \\
\hline Electricidad, gas, agua & - & - & - & 1503,3 \\
\hline Minería & 100,0 & 427,6 & 3976,3 & 1509,7 \\
\hline Total nacional & 100,0 & 189,2 & 1383,8 & 238,5 \\
\hline
\end{tabular}

Fuente: Organización Internacional del Trabajo (OIT) y C. Lagos, "Desarrollo inclusivo. Matriz de insumo-producto sectorial en una economía heterogénea: Chile 2003”, Proyecto Chile 21. Desarrollo incluyente, Santiago de Chile, Fundación Chile 21, 2008.

a Corresponde al valor bruto de la producción por ocupado.

\footnotetext{
${ }^{6}$ En los establecimientos pequeños, la mayor parte del empleo corresponde a actividades informales. De ahí en adelante, estos establecimientos se asimilan al sector informal.
} 
En cambio, el nivel de productividad de los sectores aumenta en la medida en que mejora su capacidad de absorción de empleo formal en establecimientos de tamaño mediano y grande (véase el cuadro 2a). Así, en el estrato de productividad intermedia, formado por los sectores de la construcción, el transporte y la industria, la proporción de ocupados formales como proporción del empleo total, ${ }^{7}$ o tasa de formalidad, se sitúa entre el $53,2 \%$ y el 59,5\%; en el segmento de productividad alta, al que pertenecen los sectores de electricidad, finanzas y minería, dicha tasa alcanza al 89\%. Esto indica que en la medida en que aumente la productividad media de estos sectores, mayor será la absorción de empleo formal.

\section{Las relaciones intersectoriales en condiciones de heterogeneidad productiva}

La identificación de las articulaciones económicas según niveles de productividad se basa en la información de las matrices de insumo-producto publicadas por el Banco Central de Chile (2003). ${ }^{8}$

CUADRO 2A

Chile: distribución de los ocupados según sectores y tamaño de las empresas, 2003 (En porcentajes)

\begin{tabular}{lrrrr}
\hline \multirow{2}{*}{ Sector } & \multicolumn{4}{c}{ Tamaño de la empresa } \\
\cline { 2 - 5 } & Pequeña & Mediana & Grande & Total \\
\hline Productividad baja & 51,8 & 34,3 & 13,9 & 100,0 \\
Agricultura & 46,7 & 25,7 & 27,6 & 100,0 \\
Servicios comunales & 59,1 & 21,2 & 19,7 & 100,0 \\
Comercio & & & & \\
Productividad mediana & 46,8 & 36,4 & 16,8 & 100,0 \\
Construcción & 45,4 & 30,7 & 24,1 & 100,0 \\
Transporte-comercio & 40,5 & 34,0 & 25,5 & 100,0 \\
Manufactura & & & & \\
Productividad alta & - & 69,5 & 30,5 & 100,0 \\
Establecimientos financieros & - & - & 100,0 & 100,0 \\
Electricidad, gas y agua & 10,6 & 19,6 & 69,8 & 100,0 \\
Minería & & & & \\
\hline Total & 45,1 & 31,0 & 23,9 & 100,0 \\
\hline
\end{tabular}

Fuente: Organización Internacional del Trabajo (OIT) y C. Lagos, "Desarrollo inclusivo. Matriz de insumo-producto sectorial en una economía heterogénea: Chile 2003", Proyecto Chile 21. Desarrollo incluyente, Santiago de Chile, Fundación Chile 21, 2008.

\footnotetext{
${ }^{7}$ Corresponde al porcentaje de los ocupados en empresas medianas y grandes sobre el total de cada sector.

${ }^{8}$ Véase su Compilación de Referencia 2003, de aquí en adelante "CdR" (Banco Central de Chile, 2003).
}

Los resultados se lograron a partir de una matriz sectorial de la economía chilena que considera nueve ramas de actividad desagregadas en tres niveles de productividad (baja, media y alta), la distribución del valor agregado y la demanda final de estas actividades o sectores. A nivel de esta última, el consumo interno incluye el consumo de bienes y servicios nacionales de los hogares y del gobierno. Por su parte, el consumo de los hogares se descompone en estratos alto, medio y bajo según su nivel de ingreso per cápita. ${ }^{9}$

\section{a) La matriz de relaciones intersectoriales según tamaño de la empresa}

A partir de la metodología indicada se obtuvo una matriz resumida para el año 2003, que incluye las relaciones económicas entre los tres estratos definidos en función del tamaño de las empresas, esto es, de su nivel de productividad.

Mientras que el análisis de las diferencias en materia de productividad por rama de actividad económica muestra la heterogeneidad intra e intersectorial, en lo que sigue solo se examinan las diferencias de productividad según el tamaño de la empresa.

Los datos muestran que en 2003 la economía chilena generó una producción de 97.400 millones de pesos (véase el cuadro 3). Desde el punto de vista del destino de la producción se observa que 38.000 millones corresponden a producción intermedia, 25.700 millones a consumo de los hogares, 6.100 millones a consumo del gobierno, 8.200 millones a inversión bruta y 17.500 millones a exportaciones.

$\mathrm{Al}$ considerar el origen de la producción $(97.400$ millones de pesos), se observa que el valor agregado alcanza a 48.800 millones (incluye 2.100 millones en impuestos, 21.100 millones en salarios y 25.600 millones en remuneración del capital), más el consumo intermedio que asciende a 48.700 millones (38.200 millones en insumos nacionales y 10.500 millones en insumos importados). Como lo indican los datos (véase el cuadro 3),

\footnotetext{
${ }^{9} \mathrm{El}$ estrato bajo (ingreso inferior al $60 \%$ de la mediana) incluye un $26,4 \%$ de la población, el estrato medio (ingreso entre el $60 \%$ de la mediana y el promedio) concentra un $48,3 \%$ y el estrato alto (ingreso superior al promedio) un $25,3 \%$ de ella. El consumo de los hogares a nivel agregado lo proporciona la CdR 2003. Sin embargo, para su apertura a nivel de deciles (necesaria para la agrupación realizada), y a falta de información más actualizada, se utilizó la información del Instituto Nacional de Estadísticas (INE, 1998) sobre el presupuesto familiar. Como se sabe que esta encuesta tiene un sesgo de subestimación de los ingresos a nivel de los hogares, se ajustó el consumo según decil de acuerdo con la distribución por el decil de ingreso autónomo que proporciona la Encuesta de Caracterización Socioeconómica Nacional (CASEN, 2003).
} 
la mayor parte de la generación de la producción total (97.400 millones) corresponde al sector o estrato de empresas grandes (77.900 millones). Algo semejante ocurre con la producción intermedia. Por otra parte, la mayor parte del consumo de los hogares corresponde al de los estratos de altos ingresos, a cuya producción concurren con una fracción significativa los estratos de empresas pequeñas y medianas.

No obstante que la producción y el consumo se concentran en los sectores de alta productividad e ingresos, respectivamente, la mayor parte del empleo es generada por los estratos de productividad baja y media, esto es, 4,3 millones sobre un empleo total de 5,6 millones. De ahí que los datos muestren marcados desniveles de productividad intersectorial (véase el cuadro 3 ).

\section{b) La producción intermedia: escasa integración productiva}

En la matriz estructural (véase el cuadro 3a) se observa el alto grado de heterogeneidad que caracteriza a la economía chilena. A nivel de las relaciones intermedias, se aprecia que los sectores de productividad elevada producen un $83,3 \%$ de los bienes y servicios intermedios, cifra que alcanza solamente al 8,6\% en el caso de las empresas de baja productividad y al $8,1 \%$ en las de productividad media.

Por otra parte, el gasto en insumos de las empresas de productividad baja y mediana proviene de las empresas de alta productividad, ya que un $71 \%$ y un $77 \%$, respectivamente, de su consumo intermedio nacional es suministrado por ellas (véase el cuadro 3d).

En suma, casi la totalidad de la producción intermedia es generada por las grandes empresas, mientras que la participación de las empresas pequeñas y medianas es muy reducida. Asimismo, la demanda de bienes y servicios intermedios se concentra en las empresas de productividad elevada, lo que revela la limitada capacidad de las empresas pequeñas y medianas de proveer insumos de manera competitiva.

De ahí el diverso grado de participación del consumo intermedio en el valor bruto de la producción, que en el caso de los sectores de productividad baja y mediana se aproxima al $40 \%$ y en el de las empresas de alta productividad al $52 \%$ (véase el cuadro $3 \mathrm{~b}$ ).

Estos datos revelan la falta de integración de la economía, que afecta especialmente a las empresas de productividad baja y mediana. La falta de densidad del tejido productivo se manifiesta en relaciones intersectoriales muy incompletas en materia de articulación de la producción intermedia. c) El consumo: concentración de la producción y del ingreso

En esta materia se consideran dos aspectos diferentes. Por una parte, se examina la participación de los distintos estratos de productividad en la producción de los bienes y servicios de consumo y, por otra, se evalúa la importancia de los hogares con diferente nivel de ingreso (bajo, medio y alto) en el consumo total y, por tanto, en la determinación de los niveles de producción de los diversos tamaños de empresa.

Los datos muestran que una proporción elevada del consumo de los hogares $(73,4 \%)$ corresponde a bienes proporcionados por establecimientos de gran tamaño. Esto se debe a que, independientemente de su nivel de ingreso (bajo, medio o alto), los hogares destinan la mayor parte del gasto a bienes y servicios producidos por los sectores de alta productividad (véase el cuadro 3d). En este contexto, la participación de las empresas pequeñas y medianas en el consumo total de los hogares solo alcanza al $18,1 \%$ y al $8,5 \%$, respectivamente.

Por otra parte, y como consecuencia de la concentración de los salarios elevados y de parte del excedente bruto en los sectores de alta productividad, el gasto de los hogares de ingreso alto representa un 58,4\% del consumo total, cifra que se reduce al $30,4 \%$ en el caso de aquellos de ingreso medio y al $11,2 \%$ en el de los hogares de ingreso bajo ${ }^{10}$ (véase el cuadro $3 \mathrm{c}$ ).

Los datos también muestran que el consumo del gobierno es aún más concentrado que el de los hogares, dado que un $98,7 \%$ de los bienes y servicios consumidos por las entidades públicas — prácticamente la totalidad- es producido por el segmento de empresas de alta productividad (véase el cuadro $3 b$ ).

\section{d) La inversión y las exportaciones: dinámica concentradora}

La heterogeneidad productiva también es elevadísima en materia de inversiones y exportaciones. El 86,4\% de la producción de bienes de capital se concentra en empresas grandes, limitándose al $7 \%$ la participación de las empresas pequeñas y al 6,6\% la de las empresas medianas.

Por otra parte, las empresas de alta productividad producen un $85 \%$ de las exportaciones totales, cifra que

\footnotetext{
${ }^{10} \mathrm{El}$ estrato bajo (ingreso inferior al $60 \%$ de la mediana) incluye un $26,4 \%$ de la población, el estrato medio (ingreso entre el $60 \%$ de la mediana y el promedio) concentra un $48,3 \%$ y el estrato alto (ingreso superior al promedio) un $25,3 \%$ de ella.
} 


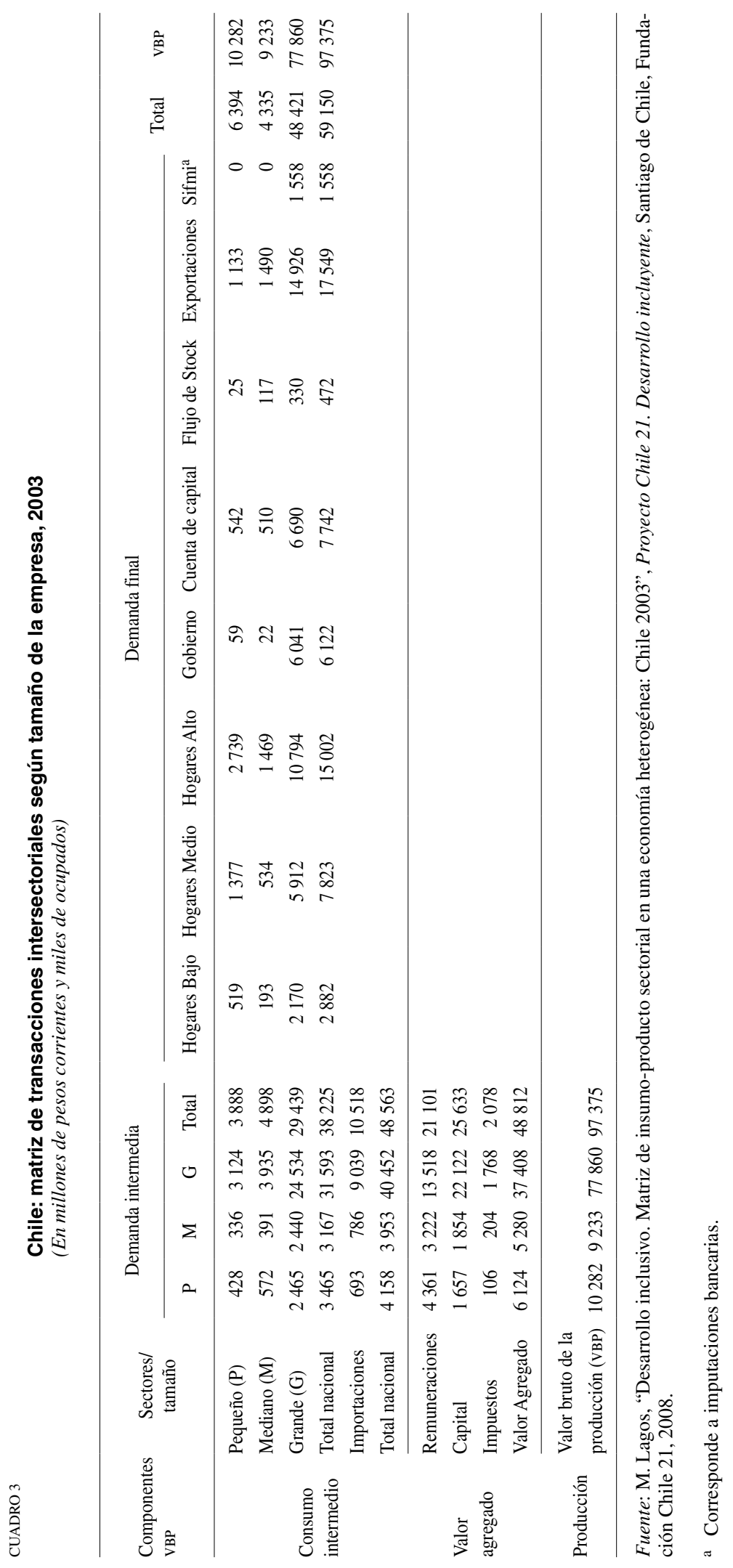




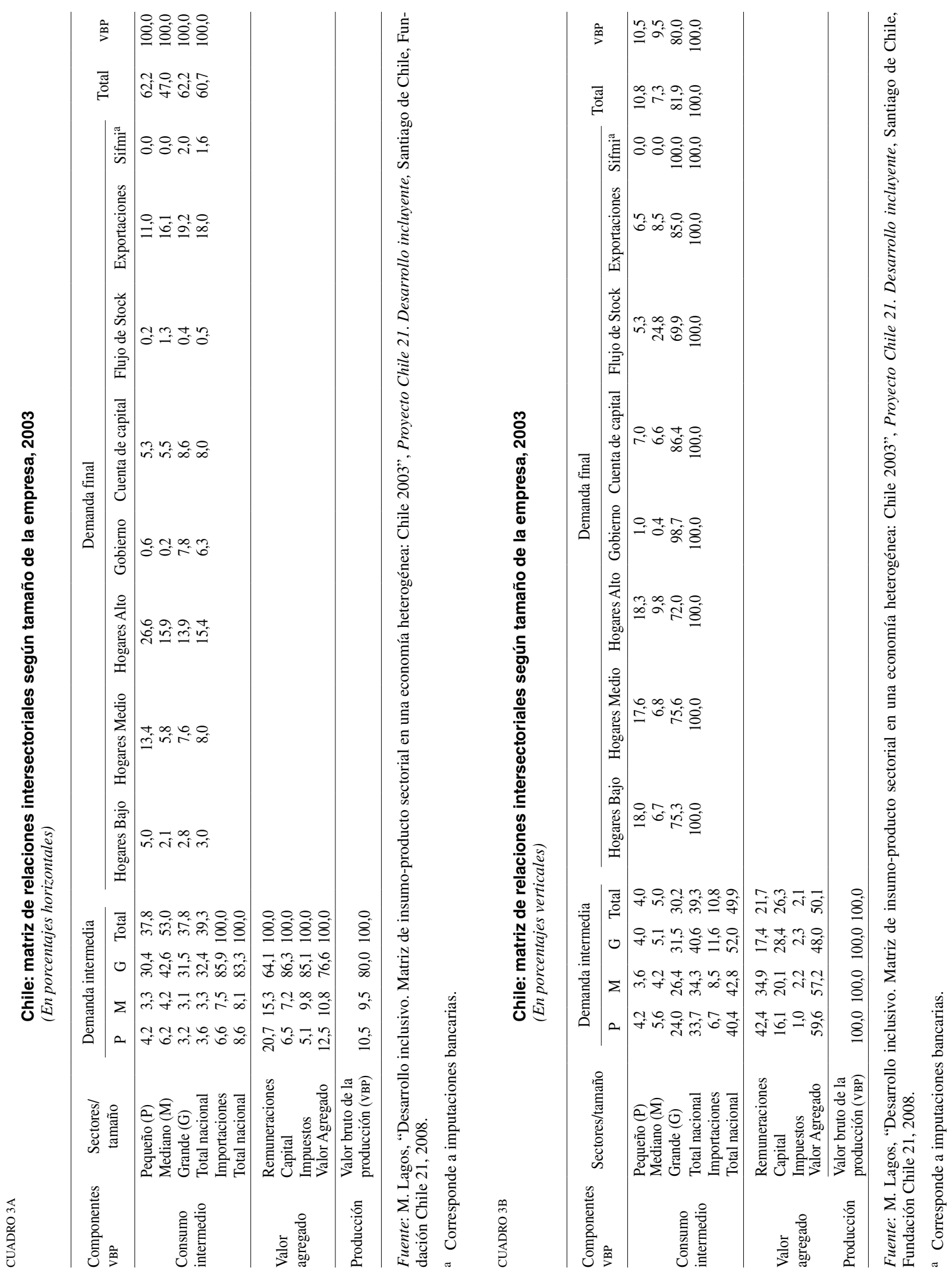


CUADRO 3C

Chile: matriz de relaciones intersectoriales y del consumo

según tamaño de la empresa, 2003

(Composición porcentual demanda intermedia y consumo de hogares, horizontal)

\begin{tabular}{|c|c|c|c|c|c|c|c|c|c|}
\hline \multirow{2}{*}{$\begin{array}{l}\text { Componente } \\
\text { VBP }\end{array}$} & \multirow{2}{*}{$\begin{array}{l}\text { Sectores/ } \\
\text { tamaño }\end{array}$} & \multicolumn{4}{|c|}{ Demanda intermedia } & \multicolumn{4}{|c|}{ Consumo de los hogares } \\
\hline & & $\mathrm{P}$ & M & G & Total & Bajo & Medio & Alto & Total \\
\hline \multirow{4}{*}{$\begin{array}{l}\text { Consumo } \\
\text { intermedio }\end{array}$} & Pequeño $(\mathrm{P})$ & 11,0 & 8,6 & 80,3 & 100,0 & 11,2 & 29,7 & 59,1 & 100,0 \\
\hline & Mediano (M) & 11,7 & 8,0 & 80,4 & 100,0 & 8,8 & 24,3 & 66,9 & 100,0 \\
\hline & Grande $(\mathrm{G})$ & 8,4 & 8,3 & 83,8 & 100,0 & 11,5 & 31,3 & 57,2 & 100,0 \\
\hline & Total & 9,1 & 8,3 & 82,6 & 100,0 & 11,2 & 30,4 & 58,4 & 100,0 \\
\hline
\end{tabular}

Fuente: M. Lagos, "Desarrollo inclusivo. Matriz de insumo-producto sectorial en una economía heterogénea: Chile 2003”, Proyecto Chile 21. Desarrollo incluyente, Santiago de Chile, Fundación Chile 21, 2008.

Nota: $\mathrm{VBP}=$ Valor bruto de la producción.

CUADRO 3D

Chile: matriz de relaciones intersectoriales y del consumo según tamaño de la empresa, 2003

(Composición porcentual demanda intermedia y consumo de hogares, vertical)

\begin{tabular}{|c|c|c|c|c|c|c|c|c|c|}
\hline \multirow{2}{*}{$\begin{array}{l}\text { Componente } \\
\text { VBP }\end{array}$} & \multirow{2}{*}{$\begin{array}{l}\text { Sectores/ } \\
\text { tamaño }\end{array}$} & \multicolumn{4}{|c|}{ Demanda intermedia } & \multicolumn{4}{|c|}{ Consumo de los hogares } \\
\hline & & $\mathrm{P}$ & M & G & Total & Bajo & Medio & Alto & Total \\
\hline \multirow{4}{*}{$\begin{array}{l}\text { Consumo } \\
\text { intermedio }\end{array}$} & Pequeño (P) & 12,4 & 10,6 & 9,9 & 10,2 & 18,0 & 17,6 & 18,3 & 18,1 \\
\hline & Mediano (M) & 16,5 & 12,3 & 12,0 & 12,9 & 6,7 & 6,8 & 9,7 & 8,5 \\
\hline & Grande (G) & 71,1 & 77,1 & 78,1 & 76,9 & 75,3 & 75,6 & 72,0 & 73,4 \\
\hline & Total & 100,0 & 100,0 & 100,0 & 100,0 & 100,0 & 100,0 & 100,0 & 100,0 \\
\hline
\end{tabular}

Fuente: M Lagos, "Desarrollo inclusivo. Matriz de insumo-producto sectorial en una economía heterogénea: Chile 2003", Proyecto Chile 21. Desarrollo incluyente, Santiago de Chile, Fundación Chile 21, 2008.

Nota: $\mathrm{VBP}=$ Valor bruto de la producción .

alcanza al 6,5\% en el caso de las empresas pequeñas y a un $8,5 \%$ en el de las medianas (véase el cuadro $3 b$ ).

Sobre la base de estos antecedentes es posible comprender por qué la apertura comercial que ha logrado el país no se ha traducido en beneficios directos para las empresas pequeñas y medianas: i) el conjunto de las empresas de tamaño reducido (pequeñas y medianas) tiene escasa participación en el total de las exportaciones $(15 \%)$, ii) si llegaran a aumentar las exportaciones de estos sectores, la debilidad del tejido productivo conduciría a que solo un $26 \%$ del consumo intermedio de las empresas pequeñas y medianas provendría del sector de empresas de igual tamaño y el restante $74 \%$ de las empresas grandes y iii) cuando aumenta la producción de las empresas de alta productividad - por ejemplo, para abastecer al mercado externo-, su demanda de insumos recae preferentemente en empresas de igual tamaño $(78,1 \%)$.
En estas condiciones, si se desea convertir a las empresas pequeñas y medianas en proveedoras de las empresas grandes orientadas al mercado externo, será preciso asignar importantes recursos de inversión para mejorar sustancialmente la integración del aparato productivo. Cuando la estructura productiva es heterogénea, la estrategia de crecimiento centrado en las exportaciones (export-led growth), en un caso muy exitoso, ha demostrado ser claramente insuficiente para lograr un desarrollo equilibrado y equitativo.

\section{Valor agregado y distribución primaria del ingreso}

La heterogeneidad económica que se aprecia a nivel de las relaciones intermedias y de la demanda final se expresa también en el ámbito del trabajo, esto es, en el empleo y los salarios. 
Una elevada proporción del valor agregado (descontados los impuestos) de los sectores de baja productividad corresponde al pago de remuneraciones al trabajo, que representa un $72,5 \%$ del valor agregado de las empresas pequeñas y un $63,5 \%$ del de las medianas (véase el cuadro $3 b$ ). Sin embargo, en estos sectores ambas remuneraciones representan solo un $20,7 \%$ y un $15,3 \%$, respectivamente, del total de los salarios. Asimismo, se observa que las actividades de baja productividad (empresas pequeñas y medianas) demandan un $47,6 \%$ y un $28,8 \%$, respectivamente, del empleo total de la economía. ${ }^{11}$

En cambio, en las empresas de alta productividad las remuneraciones al trabajo constituyen un $37,9 \%$ del valor agregado (descontados los impuestos) y representan un $64,1 \%$ del total de salarios de la economía, en tanto que el empleo generado alcanza solo al 23,6\% de este (véase el cuadro 3).

En este contexto, las diferencias de salario se explican en gran medida por la desigual productividad del trabajo de los diferentes estratos de la economía. En términos agregados, mientras que en los sectores de bajo rendimiento la productividad del trabajo es de 3,8 millones de pesos, en los de alto rendimiento ella se eleva a 58 millones. Esto es, la productividad por trabajador de los sectores de alto rendimiento es casi 15 veces superior a la que registran los de bajo rendimiento. Esta diferencia en materia de productividad conduce a que la remuneración bruta por ocupado de las empresas pequeñas y medianas sea entre seis y cinco veces inferior a la que perciben los trabajadores de las empresas de alta productividad y explica, en gran medida, la inequidad distributiva de la economía chilena y su persistencia en el tiempo.

Por otra parte, la participación del excedente bruto de capital en el valor agregado alcanza al $63,1 \%$. El grueso del pago al capital es percibido por las empresas de alta productividad, que concentran aproximadamente un $86,3 \%$ del excedente bruto de capital de la economía. La elevada participación de los establecimientos grandes en los salarios y en el excedente bruto significa que generan la mayor parte $(76,6 \%)$ del valor agregado de la economía.

En suma, se observa una alta concentración de los salarios y del excedente bruto de capital en las grandes

\footnotetext{
${ }^{11}$ Ello se debe a las diferencias del salario promedio de los ocupados en los distintos sectores. Estas reflejan, por una parte, las marcadas diferencias de productividad entre las empresas pequeñas y medianas y las grandes (véase el cuadro 3) y, por otra, que los trabajadores de estas últimas tienen un mayor grado de organización.
}

empresas, en circunstancias de que la gran mayoría de la población que trabaja en las empresas de tamaño pequeño y mediano $(76,4 \%)$ percibe una porción muy reducida del valor agregado $(23,3 \%)$.

\section{La dinámica de la estructura económica: el dominio de las empresas grandes}

Una de las ventajas del uso de matrices de insumoproducto es la posibilidad de simular la reacción de la economía ante diferentes escenarios. Los coeficientes económicos de una de estas matrices permiten identificar cuál es el aporte de cada uno de los factores productivos (insumos, capital y trabajo) a la producción de un bien que es finalmente ofrecido en la economía.

Si la producción aumenta, se incrementará proporcionalmente la demanda de factores productivos. ${ }^{12}$ Este proceso es iterativo para cada sector económico que es a la vez oferente y demandante de bienes, servicios o ambos. De este modo, el uso de los mecanismos de las matrices inversas de insumo-producto permite simular impactos estáticos de diferentes cambios de la demanda agregada en la economía y comprobar cómo varía la producción total en una economía heterogénea, como es el caso de la chilena.

A continuación se miden los efectos que tendría, por ejemplo, un aumento del $10 \%$ de la demanda final en la producción de los diferentes estratos productivos de la economía. Al respecto, una cuestión interesante es determinar cuánto crecería la economía si: i) la demanda agregada de las empresas pequeñas y medianas aumentara en la tasa indicada y ii) si la demanda agregada de las empresas de alta productividad experimentara el mismo incremento.

Las estimaciones muestran que si la demanda final del conjunto de las empresas pequeñas aumentara un $10 \%$, la producción de la economía solo se elevaría un $1 \%$. Esto obedece a la escasa ponderación de los sectores de baja productividad en las relaciones intermedias y en la demanda final.

Por otra parte, si la demanda de las empresas de alta productividad se incrementara un $10 \%$, ello arrastraría al resto de los sectores a aumentar su producción (mediante la demanda de insumos), estimulando de preferencia a los sectores de igual nivel de productividad, ${ }^{13}$ cuya producción crecería un $9,4 \%$.

\footnotetext{
12 En el supuesto de que la tecnología es fija (lo que a corto plazo es razonable).

${ }^{13}$ Las empresas de alta productividad producen un $64 \%$ del total de las transacciones intermedias.
} 
Por último, las estimaciones destacan la escasa importancia de los sectores de mediana productividad en los resultados obtenidos. Al respecto, es preciso tener presente que el conjunto de los sectores de mediana y baja productividad representan un $17 \%$ del consumo intermedio y un $23 \%$ del valor bruto de la producción. Si la demanda de bienes y servicios de estos sectores creciera un $10 \%$ (por ejemplo, mediante un plan de inversiones, el fomento de las exportaciones o el aumento del gasto privado), la producción total de la economía solo se elevará un $1,7 \% .^{14}$

En suma, la economía de Chile, y por consiguiente la sociedad chilena, se encuentran divididos en mundos diferenciados y escasamente articulados. El primero, de alta productividad, es el que impulsa a la economía y paga buenos salarios, mientras que los restantes, de mediana y baja productividad, no influyen mayormente en el crecimiento por mucho que absorben la mayor parte del empleo. Por tanto, y como se ha postulado, la heterogeneidad se reproduce aun en condiciones de crecimiento económico acelerado.

\section{Las políticas redistributivas y distributivas: limitaciones del gasto social}

La mala distribución del ingreso generada en el mercado laboral como resultado de la heterogeneidad productiva que caracteriza el funcionamiento de la economía, ha sido sistemáticamente corregida por la política de gasto social.

Se considera que la política social es uno de los mecanismos redistributivos que tienen por finalidad mejorar el nivel de vida de las personas, especialmente el de los grupos sociales de menores recursos, puesto que a los ingresos provenientes del trabajo de los hogares agrega subsidios entre los que cabe destacar los relativos a salud, educación y vivienda, además de transferencias monetarias. Sin embargo, esta clase de política entraña varios riesgos. El primero es que la expansión de esta política redistributiva depende de la situación fiscal, sobre todo de la carga tributaria. En segundo lugar, la elevada incidencia que han alcanzado los recursos del gasto social en el ingreso de los hogares más pobres hace que los ingresos del trabajo tengan escasa importancia y que, por tanto, el nivel de vida de las familias y de las

\footnotetext{
${ }^{14}$ Cabe recordar que en iguales condiciones la producción de las empresas de baja productividad (pequeñas) consideradas aisladamente aumentaría un $1 \%$.
}

personas dependa cada vez más de los recursos públicos antes que los del trabajo (Infante, 2007a).

Los datos muestran que en los hogares pertenecientes al primer quintil solo un $28,8 \%$ del ingreso total proviene del trabajo (véase el cuadro 4). Esta cifra se eleva al 52,3\% en el caso de los hogares del segundo quintil. Al considerar ambos quintiles $(40 \%$ de la población) se comprueba que solo una parte $(40,5 \%)$ del ingreso total de estos hogares se origina en el trabajo, en tanto una fracción mayoritaria $(59,5 \%)$ proviene del gasto social.

En estas condiciones, la inserción social de un gran número de personas se consigue básicamente proporcionándoles un nivel de ingresos que posibilita un nivel mínimo aceptable de consumo, pero que no se articula con la sociedad por medio del trabajo, que es el principal factor de integración social y de ciudadanía.

Por su parte, los bajos niveles de ingreso per cápita de los hogares obedecen a la débil inserción laboral de las personas en condiciones de trabajar. En efecto, los datos indican que el 48,3\% de los ocupados pertenecientes a los hogares del quintil I trabaja en actividades de baja productividad y un $14,5 \%$ lo hace en sectores de productividad media-baja (véase el cuadro 5). Esto es, un $62,8 \%$ corresponde a estratos de reducida productividad, cifra que alcanza al $56,7 \%$ en el caso de los ocupados pertenecientes a los hogares del quintil II. En suma, cerca de un 60\% de los trabajadores que pertenecen a los hogares menos favorecidos del país carece de un trabajo que tenga un buen nivel de productividad y una remuneración digna. A menos que cambie esta situación, habrá que destinar permanentemente — vía gasto social- un volumen importante y creciente de recursos a la transferencia de ingresos a los sectores de menores recursos para que alcancen un nivel de vida aceptable. Sin embargo, este tipo de política podría depender de la disponibilidad de recursos fiscales debido, entre otros motivos, a la carga impositiva.

Por consiguiente, sería imperioso ir complementando progresivamente las políticas redistributivas con otras de carácter distributivo, de modo de poder reducir las brechas de productividad y, por ende, mejorar el ingreso primario (autónomo) de los sectores menos favorecidos. Las políticas distributivas contribuirían así a disminuir efectivamente la desigualdad tanto de ingresos como de acceso a oportunidades entre los diversos grupos que componen la estructura social, según se indica más adelante. 
CUADRO 4

Chile: origen del ingreso total de los hogares según quintiles, 2006

(En porcentajes)

\begin{tabular}{|c|c|c|c|c|c|c|}
\hline \multirow{2}{*}{ Ingresos y subsidios } & \multicolumn{6}{|c|}{ Quintil autónomo nacional } \\
\hline & I & II & III & IV & $\mathrm{V}$ & Total \\
\hline Ingreso del trabajo en el hogar & 28,8 & 52,3 & 66,0 & 77,2 & 86,4 & 78,5 \\
\hline $\begin{array}{l}\text { Ingreso promedio autónomo (a) } \\
\text { Pensiones asistenciales (PASIS) } \\
\text { Subsidio familiar (SUF) } \\
\text { Bono Chile solidario (CHS) }\end{array}$ & $\begin{array}{r}35,0 \\
7,3 \\
1,8 \\
0,5\end{array}$ & $\begin{array}{r}61,6 \\
2,5 \\
0,5 \\
0,2\end{array}$ & $\begin{array}{r}78,2 \\
1,2 \\
0,2 \\
0,1\end{array}$ & $\begin{array}{r}90,2 \\
0,5 \\
0,1 \\
0,0\end{array}$ & $\begin{array}{r}99,2 \\
0,1 \\
0,0 \\
0,0\end{array}$ & $\begin{array}{r}91,2 \\
0,7 \\
0,2 \\
0,0\end{array}$ \\
\hline Subsidio al consumo de agua potable (SAP) & 0,6 & 0,4 & 0,3 & 0,1 & 0,0 & 0,1 \\
\hline $\begin{array}{l}\text { Subsidios focalizados } \\
\text { Asignación familiar } \\
\text { Subsidio de cesantía }\end{array}$ & $\begin{array}{r}10,2 \\
1,5 \\
0,1\end{array}$ & $\begin{array}{l}3,6 \\
1,5 \\
0,1\end{array}$ & $\begin{array}{l}1,8 \\
0,9 \\
0,1\end{array}$ & $\begin{array}{l}0,7 \\
0,4 \\
0,0\end{array}$ & $\begin{array}{l}0,1 \\
0,1 \\
0,0\end{array}$ & $\begin{array}{l}1,0 \\
0,3 \\
0,0\end{array}$ \\
\hline Subsidios no focalizados & 1,6 & 1,6 & 1,0 & 0,4 & 0,1 & 0,3 \\
\hline Total subsidios $(b)$ & 11,8 & 5,2 & 2,8 & 1,1 & 0,2 & 1,3 \\
\hline $\begin{array}{l}\text { Ingresos monetarios }(a+b) \\
\text { Alquiler imputado } \\
\text { Educación parvularia } \\
\text { Educación Básica } \\
\text { Educación Media } \\
\text { Educación de adultos }\end{array}$ & $\begin{array}{r}46,7 \\
5,1 \\
3,7 \\
20,0 \\
7,8 \\
0,4\end{array}$ & $\begin{array}{r}66,9 \\
5,1 \\
2,5 \\
12,2 \\
6,3 \\
0,4\end{array}$ & $\begin{array}{r}80,9 \\
5,4 \\
1,7 \\
7,6 \\
3,9 \\
0,2\end{array}$ & $\begin{array}{r}91,3 \\
5,0 \\
0,9 \\
4,3 \\
2,2 \\
0,1\end{array}$ & $\begin{array}{r}99,3 \\
3,2 \\
0,2 \\
0,9 \\
0,4 \\
0,0\end{array}$ & $\begin{array}{r}92,5 \\
4,6 \\
0,6 \\
3,1 \\
1,4 \\
0,1\end{array}$ \\
\hline Total educación (c) & 31,9 & 21,4 & 13,4 & 7,5 & 1,5 & 5,2 \\
\hline $\begin{array}{l}\text { Subsidio por atenciones } \\
\text { Programa de alimentación complementaria } \\
\text { Programa de alimentación del adulto mayor }\end{array}$ & $\begin{array}{r}20,6 \\
0,6 \\
0,2\end{array}$ & $\begin{array}{r}11,3 \\
0,4 \\
0,1\end{array}$ & $\begin{array}{l}5,3 \\
0,2 \\
0,1\end{array}$ & $\begin{array}{l}1,0 \\
0,1 \\
0,1\end{array}$ & $\begin{array}{r}-0,9 \\
0,0 \\
0,0\end{array}$ & $\begin{array}{l}2,1 \\
0,1 \\
0,0\end{array}$ \\
\hline Total salud $(d)$ & 21,4 & 11,8 & 5,6 & 1,2 & $-0,9$ & 2,2 \\
\hline Ingreso total $(a+b+c+d)$ & 100,0 & 100,0 & 100,0 & 100,0 & 100,0 & 100,0 \\
\hline
\end{tabular}

Fuente: Ministerio de Planificación (MIDEPLAN), "Distribución del ingreso e impacto distributivo del gasto social”, serie Análisis de resultados de la Encuesta CASEN, № 2, Santiago de Chile, 2006; y "Metodología de valorización de los subsidios en salud, educación y monetarios", Casen 2006, Santiago de Chile, 2006.

CUADRO 5

Chile: ocupados según tamaño de la empresa y quintiles de ingreso, 2006 (En porcentajes)

\begin{tabular}{|c|c|c|c|c|c|c|}
\hline \multirow{2}{*}{ Productividad/tamaño de empresa } & \multicolumn{6}{|c|}{ Quintil autónomo nacional } \\
\hline & I & II & III & IV & $\mathrm{V}$ & Total \\
\hline Productividad Alta & 17,2 & 21,3 & 26,9 & 27,7 & 35,8 & 27,2 \\
\hline Empleados y obreros (empresas de 200 personas y más) & 16,6 & 20,7 & 25,7 & 26,1 & 29,2 & 24,7 \\
\hline Empleadores (empresas de 200 personas y más) & 0,0 & 0,0 & 0,0 & 0,0 & 0,3 & 0,1 \\
\hline Cuenta propia (profesionales y técnicos) & 0,6 & 0,6 & 1,2 & 1,6 & 6,3 & 2,4 \\
\hline Productividad Media & 34,6 & 37,1 & 33,6 & 32,3 & 29,4 & 33,0 \\
\hline Media baja & 20,1 & 21,9 & 19,1 & 18,0 & 16,3 & 18,8 \\
\hline Media alta & 14,5 & 15,2 & 14,5 & 14,3 & 13,1 & 14,2 \\
\hline Productividad Baja & 48,2 & 41,5 & 39,5 & 39,9 & 34,9 & 39,8 \\
\hline Empleados y obreros (empresas de 6 a 9 personas) & 7,8 & 6,1 & 6,3 & 4,4 & 3,2 & 5,2 \\
\hline Empleadores (empresas de 6 a 9 personas) & 0,1 & 0,1 & 0,2 & 0,3 & 1,8 & 0,6 \\
\hline Informal & 40,3 & 35,3 & 33,0 & 35,2 & 29,9 & 34,0 \\
\hline Empleadores (empresas de 5 personas o menos) & 0,3 & 0,5 & 1,0 & 1,8 & 5,0 & 2,0 \\
\hline Empleados y obreros (empresas de 5 personas o menos) & 15,3 & 13,0 & 10,5 & 7,2 & 4,7 & 9,3 \\
\hline Cuenta propia (no prof. y técnicos) y fam. no rem. & 24,7 & 21,8 & 21,6 & 26,2 & 20,1 & 22,7 \\
\hline Total & 100,0 & 100.0 & 100.0 & 100,0 & 100,0 & 100,0 \\
\hline
\end{tabular}

Fuente: elaboración propia sobre la base de datos del Ministerio de Planificación (MIDEPLAN) y la Encuesta de Caracterización Socioeconómica Nacional (CASEN) 2006. 


\section{V}

\section{Desarrollo con inserción social}

Como se ha señalado, el actual modelo económico descansa en la redistribución a posteriori de una parte (menor) de los ingresos generados por el crecimiento. Para avanzar con equidad creciente es preciso concebir una estrategia de desarrollo renovada cuyo objetivo central sea una inserción laboral productiva y social satisfactoria en el proceso de producción y en la propia estructura y funcionamiento del sistema socioeconómico, lo que aseguraría una mejor distribución primaria del ingreso al momento de su gestación (Sunkel e Infante, 2006).

Lo anterior implica concebir la dinámica del desarrollo no solo en función de los sectores de exportación modernos, sino también, y de manera categórica, de aquellos de producción de menor productividad. La estrategia actual funciona bastante bien cuando se trata de la primera tarea, pero hay que dinamizarla con productos de creciente valor agregado y densidad tecnológica. Sin embargo, subyace a esta estrategia la errada concepción de que en el país hay una relativa homogeneidad productiva, lo cual impide percibir la excepcional prioridad e importancia que debiera otorgarse a la segunda tarea. Se trataría entonces de una estrategia renovada cuyos pilares fundamentales consistirían en acentuar el actual proceso exportador aumentando su diversificación dinamizadora $y$, por otra parte, en atenuar la heterogeneidad productiva reduciendo las diferencias de productividad según el tamaño de las empresas, sectores y regiones.

Por tanto, habría que pensar en poner en marcha un ambicioso programa de transformación estructural a largo plazo ( 15 a 20 años) que permitiera que los sectores menos avanzados aumentaran gradualmente la productividad y los ingresos de quienes trabajan en ellos y mejorar la calidad de vida de las familias relativamente excluidas (Infante, Molina y Sunkel, 2007).

En suma, la estrategia de desarrollo propuesta incluiría nuevas formas de acción recíproca entre el Estado y el mercado, dotadas de una visión estratégica de largo plazo, así como entre el Estado y el ciudadano, la sociedad civil, las organizaciones solidarias de base y las regiones y localidades; un mayor énfasis en la eficacia, la flexibilidad y la descentralización y una preocupación primordial por los aspectos tecnológicos, institucionales y organizativos (Sunkel, 2006c). En definitiva, se propone que la participación ciudadana tenga, en primer lugar, una expresión productiva que sirva de base y se transforme eventualmente en una mayor participación social y política de los grupos sociales relativamente excluidos.

\section{VI}

\section{Los aspectos estratégicos del desarrollo inclusivo}

Como se indicó, la dinámica disociadora y divergente que caracteriza el desarrollo actual no se soluciona con mayores tasas de crecimiento ni con una mayor y mejor utilización del gasto social. Lo que se requiere es un cambio de enfoque: políticas públicas para superar gradualmente la heterogeneidad estructural prevaleciente en los diferentes sectores y regiones de la matriz productiva y social del país, puesto que ella es el principal obstáculo para lograr el crecimiento con equidad (Sunkel e Infante, 2006). Se trata de políticas que permitan reducir en forma paulatina la asimetría entre la productividad de las actividades de punta y de aquellas de bajo nivel de rendimiento como las micro y pequeñas empresas informales, con lo cual podrían reducirse las correspondientes diferencias de salario. De esta forma se estaría contribuyendo a disminuir efectivamente la desigualdad, tanto en materia de acceso a oportunidades entre los diversos grupos que componen la estructura social como de distribución del ingreso.

Por otra parte, es inevitable que la reciente crisis financiera originada en los Estados Unidos y que se ha propagado con rapidez al resto de las economías industrializadas y emergentes afecte en forma negativa a Chile a corto plazo. Así lo demuestra el hecho de que las 
proyecciones de crecimiento se han ajustado sensiblemente a la baja y de que el desempleo va en aumento.

Dada la marcada heterogeneidad que caracteriza la estructura productiva, es previsible que la disminución del nivel de actividad afecte con mayor intensidad a los estratos de menor productividad (empresas pequeñas y medianas), que concentran la mayor parte del empleo. Como resultado de ello, es muy probable que se deteriore el mercado laboral al aumentar la informalidad y el desempleo y reducirse los salarios reales. Esto significaría que los costos de la crisis actual recaerían principalmente en los sectores de la población de ingresos medios y bajos, lo que reforzaría la tendencia a la ya mencionada concentración del ingreso.

En una primera aproximación de la estrategia de desarrollo inclusivo propuesta -muy provisional, por cierto-, se tienen en cuenta al menos cuatro elementos estrechamente relacionados entre sí: convergencia productiva, protección social garantizada, cambios institucionales necesarios y crecimiento económico sostenido con equidad. El adecuado funcionamiento de estos pilares permitiría reforzar la cohesión social al asegurar el bienestar de una proporción creciente de la población y minimizar las disparidades evitando la polarización (véase diagrama 1).

\section{La convergencia productiva}

El éxito de una estrategia para mejorar la integración de las personas depende fundamentalmente de que se supere la marcada heterogeneidad productiva que caracteriza al sistema económico. ${ }^{15}$ En las tareas de convergencia productiva o de homogeneización gradual de la productividad de los diferentes estratos de la producción, las empresas de menor tamaño (micro, pequeñas y medianas) deben cumplir un papel importante tanto para dinamizar el crecimiento y la generación de empleo como para reducir la informalidad.

Al respecto, es importante tener presente la extraordinaria experiencia de la Unión Europea, donde el logro del objetivo de convergencia productiva se basó en promover condiciones y factores que mejoraran el crecimiento y condujeran a la notable reducción lograda en la brecha entre los Estados miembros y las regiones menos desarrolladas de estos, apuntando prioritariamente a elevar la productividad y poniendo especial énfasis en el mejoramiento del entorno en que se desenvuelven las empresas pequeñas y medianas. ${ }^{16} \mathrm{~A}$ continuación se señalan algunas de las áreas críticas para el desarrollo de la convergencia productiva en Chile.

En primer lugar, hay que señalar que la homogeneización gradual de la estructura económica solo será viable si el modelo de negocios aplicado por las grandes empresas en sus relaciones con los establecimientos

\footnotetext{
${ }^{15}$ Esta es una de las principales líneas de trabajo de la CEPAL, cuyo resultado más reciente puede consultarse en CEPAL (2008).

${ }^{16}$ Al respecto, véase Unión Europea (1997) y Comisión de las Comunidades Europeas (1993). En cuanto a las políticas de homogeneización productiva en la Unión Europea, véase Infante (2008).
}

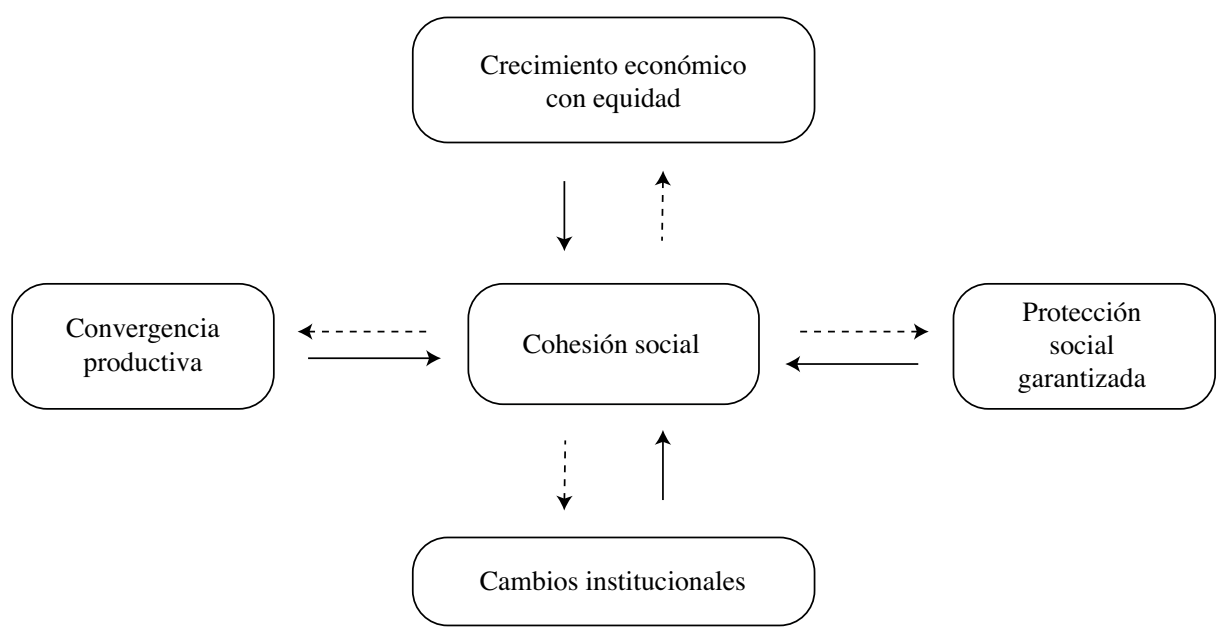

Fuente: elaboración propia. 
pequeños incluye fuertes incentivos para el desarrollo de la actividad empresarial de las empresas medianas y pequeñas.

La idea es impulsar la creación de un ambiente de mayor competitividad que permita la expansión de los negocios de las empresas pequeñas, mediante la aplicación de un conjunto de normas en favor de la competencia que velen por la proliferación de estas a largo plazo. Por otra parte, se trata de promover programas de inversión en nuevos sectores sociales, esto es, de desarrollar una "economía social" que genere empleo específicamente para los trabajadores de los sectores informales y se oriente sobre todo a satisfacer las necesidades sociales de los estratos de menores ingresos, tema ya mencionado como uno de los criterios de acción para abordar la crisis con visión de futuro. En tal sentido, cabe destacar la necesidad de un fuerte y sostenido impulso, así como de coordinación por parte del Estado, todo lo cual deberá reflejarse en la asignación de un volumen importante de recursos durante un período prolongado de tiempo. Las decisiones sobre el monto y destino de esos recursos debieran adoptarse a través del diálogo social (Infante, 2006).

Otra propuesta al respecto es constituir aglomeraciones productivas (clusters) regionales cuya estructura local se sustente en una institucionalidad sólida que pueda potenciar la capacidad innovadora; disminuir la aversión al riesgo; fortalecer la difusión de información sobre mercados, tecnologías y conocimientos técnicos (know-how); promover la capacitación de trabajadores y presentarse como fuente de acumulación de experiencias. La institucionalidad local es la que permite desarrollar sinergias y sustentar las economías de aglomeración. Así, serían los propios actores locales quienes asumirían la responsabilidad de su desarrollo (Guardia, 2007; Muñoz, 2008).

Al Estado le corresponde un papel central en la redistribución de los recursos públicos, pero a partir de una estrategia en la cual las regiones asumen el protagonismo de su propio desarrollo. Aparece aquí un aspecto fundamental que es preciso explicitar: la región, o más bien el territorio, adquiere un sentido económico y social en la medida en que se reconozca que se trata de un espacio tanto geográfico como social.

\section{Cambios institucionales}

La formulación de una nueva concepción del desarrollo nacional provista de un enfoque integral a mediano y largo plazos en que participen el Estado, la ciudadanía organizada, los trabajadores y el empresariado, exige cambios institucionales en los ámbitos económico, laboral y de diálogo social.

En lo que respecta a la institucionalidad económica, para superar uno de los obstáculos básicos que se interpone a la aplicación eficaz de la política de convergencia productiva se requiere modificar el actual "modelo de negocios", que ha terminado por debilitar a segmentos cada vez más amplios de los empresarios medianos y pequeños, ${ }^{17}$ generando estrangulamientos y la necesidad de que el Estado intervenga para resolverlos.

Las políticas públicas deben cambiar y orientarse prioritariamente a elevar la productividad, poniendo especial énfasis en el mejoramiento del entorno en que se mueven las empresas pequeñas y medianas, que son las que generan la mayor parte del empleo productivo.

El cambio institucional requiere que el nuevo modelo de negocios aplicado por las grandes empresas en sus relaciones con los establecimientos pequeños incluya, entre otras cosas, fuertes incentivos para el desarrollo de la actividad empresarial de las micro, pequeñas y medianas empresas y su integración a las aglomeraciones productivas. Por tanto, hay que impulsar la creación de un ambiente de mayor competitividad que permita la expansión de los negocios de las empresas pequeñas, desarrollando un conjunto de normas en favor de la competencia que velen por la proliferación a largo plazo de entidades empresariales de pequeña escala (Román, 2008).

La construcción de instituciones sólidas en el mercado de trabajo es otro reto importante en la formulación de una estrategia de desarrollo inclusiva y con justicia social. El nuevo marco regulatorio de la negociación colectiva debería incluir, mediante una estructura flexible, tanto el nuevo paradigma de la empresa globalizada - la externalización productiva - como la asimetría contractual entre las empresas grandes y las pequeñas, en particular en lo que dice relación con las cadenas productivas (Feres e Infante, 2007).

Las nuevas reglas de juego deberían conducir a una distribución más equitativa de los costos y de los beneficios que se captan en la comercialización de los productos finales, evitando especialmente que los bajos ingresos del trabajo y la falta de observancia de los derechos laborales continúen legitimándose como factores de competitividad. ${ }^{18}$

\footnotetext{
${ }^{17}$ Se entiende por modelo de negocios el conjunto de regulaciones y prácticas comerciales basado en el sentido común y de normas legales que posibilitan determinadas estructuras de mercado y sus modalidades operativas.

${ }^{18}$ Sobre estos temas, véase Infante (2007b).
} 
Para poder hacerse efectivo en los diferentes niveles de participación ciudadana, el nuevo diálogo social exigirá readecuar las instituciones. Con esta finalidad, debería crearse una estructura participativa mediante una red de instituciones sociales de base. Esta es tal vez la tarea más importante que enfrentan el Estado y la sociedad, para sentar las bases de un desarrollo inclusivo con mayor calidad del empleo y equidad (Sunkel e Infante, 2006).

Una iniciativa de esta naturaleza debería contar con la amplia participación del sector privado y de las organizaciones de la sociedad civil de cada región y localidad, que son los espacios en que se manifiestan en la práctica las diferencias de productividad y las características específicas que es preciso superar. Para acometer una tarea de esta magnitud habría que forjar un nuevo contrato social en que las decisiones sobre el monto y aplicación de los recursos se adopten en los niveles que corresponda por medio del diálogo social entre trabajadores, empresarios, gobierno y representantes de la sociedad civil, a fin de responder en mejor forma a las necesidades reales y a las expectativas de los ciudadanos.

\section{Protección social garantizada}

Se trata de construir una sociedad capaz de garantizar el acceso equitativo de todas las personas a las oportunidades de progreso y de protección social.

En general, la idea es que la acción conjunta del Estado, el mercado y la sociedad mejore las oportunidades de acceso al capital social necesario para alcanzar el progreso material y moral y la mejor protección social posible de las personas, de acuerdo con el nivel de ingresos y de desarrollo de los países. En este ámbito, el concepto de garantía se refiere al conjunto de oportunidades y protecciones básicas que la sociedad está en condiciones de asegurar a todas las personas por la vía de las políticas públicas (Lagos E., 2008).

El Estado es fundamentalmente responsable de formular y consensuar las políticas que mediante instrumentos públicos y privados permitan garantizar a los ciudadanos la protección de sus derechos y los recursos necesarios para ello, de acuerdo con las posibilidades de la economía. La idea es que mientras más recursos proporcione el crecimiento de la economía, mayores serán también los derechos que deben ser garantizados y exigibles. En estas condiciones, el límite de la cobertura de la protección social garantizada está dado por el grado de desarrollo sustentable. Una política social garantizada debería abarcar, entre otros aspectos, la salud, la calidad de la educación y los derechos económicos y sociales.

Aunque la persistencia, calidad e intensidad de las políticas redistributivas que se aplican, por ejemplo, en materia de educación y de salud podrían producir cambios en los elementos que condicionan la desigualdad, contribuyendo así al logro de una sociedad más equitativa, la tarea de contrarrestar la tendencia a la concentración del ingreso que se produce cuando compiten los que tienen más recursos de todo tipo con los que no han logrado acceder a un mínimo de oportunidades no debe depender exclusivamente del gasto social. En efecto, si lo que se persigue es una distribución más equitativa del ingreso, las políticas y medidas redistributivas deben combinarse con políticas de corte distributivo, como son las de convergencia productiva y los cambios institucionales propuestos, porque inciden en los orígenes mismos de los ingresos $y$, por tanto, tienen efectos permanentes (Assael, 1998).

Otro aspecto que debe tenerse presente es el tipo de ciudadano que se estaría promoviendo mediante la protección social garantizada. La idea es que la sociedad genere ciudadanos mediante el trabajo, que es el principal factor de integración social, y no como ocurre actualmente por la vía del asistencialismo, con recursos provenientes del gasto social.

\section{El crecimiento económico con equidad}

El crecimiento acelerado y sostenido de la producción de bienes y servicios de consumo es condición esencial y directa del mejoramiento de los niveles de vida de la población. Este crecimiento, que en el pasado ha sido excluyente y ha privilegiado a una minoría de la población, debe reunir una serie de requisitos especiales para que el desarrollo pueda ser inclusivo.

Desde luego, tiene que ser relativamente elevado, por cierto que bastante superior al crecimiento de la población, de modo que la sociedad pueda percibirlo claramente y se sienta estimulada a entregar su esfuerzo y cooperación en apoyo de la cohesión social. De acuerdo con la experiencia histórico-universal, es razonable prever que las tasas de crecimiento oscilen entre un $5 \%$ y un 6\% anual (Ffrench-Davis, 2003). Difícilmente podrían sostenerse tasas superiores por períodos largos sin generar presiones inflacionarias y otros desequilibrios, mientras que si ellas son inferiores resultarán poco perceptibles por la población e insuficientes en relación con sus aspiraciones y expectativas. Por otra parte, para lograr niveles razonablemente elevados de empleo se necesitan tasas de crecimiento del rango indicado. 
Condición esencial del crecimiento es la expansión de la capacidad productiva, es decir, la inversión. También de acuerdo con la experiencia histórica, para lograr las tasas de crecimiento del consumo antes señaladas ella debería superar al menos el $25 \%$ del PIB. Además, para sostener altos niveles de ocupación, fuente principal de ingresos de la mayor parte de la población, y para incorporar el progreso tecnológico, que es requisito esencial para el incremento de la productividad y la competitividad, se necesitan tasas de inversión elevadas. Por otra parte, el logro de la convergencia productiva exige invertir masivamente en la modernización y mejoramiento de la productividad de los segmentos rezagados de la estructura productiva interna.

En los países de escaso desarrollo científicotecnológico, como es el caso de Chile, el progreso tecnológico proviene fundamentalmente del exterior, incorporado en bienes y servicios de capital importados. Por consiguiente, otro requisito esencial del crecimiento incluyente es promover una marcada dinámica exportadora que permita financiar la importación de estos, como también la de bienes y servicios de consumo que el país no produzca o cuya producción nacional sea muy ineficiente, así como otros de avanzado perfeccionamiento tecnológico que la economía nacional no está en condiciones de producir y cuya demanda es muy dinámica. En otras palabras, el sector exportador viene a ser el equivalente de los sectores productores de bienes de capital y del progreso tecnológico de los países desarrollados. De ahí la importancia estratégica crítica de desarrollar exportaciones más dinámicas, más diversificadas y más estables.

Sin embargo, como es bien sabido, el patrón de exportaciones de Chile y de los países latinoamericanos en general se caracteriza por componerse fundamentalmente de materias primas o productos básicos de origen mineral, agropecuario, silvícola y pesquero que históricamente han dado muestras de escaso dinamismo $\mathrm{y}$ de gran inestabilidad en los mercados internacionales, además de una tendencia desfavorable de la relación de intercambio, que en los últimos años se ha invertido gracias a la presencia de nuevos actores en el escenario internacional.

Dada la importancia determinante de la dinámica del sector exportador, su tasa media de expansión influye decisivamente en el ritmo de crecimiento a mediano plazo de la economía, de manera que las frecuentes y agudas fluctuaciones que caracterizan a los mercados mundiales de productos básicos se traducen en una sucesión de períodos de bonanza y recesión. Estos últimos se han agudizado en las últimas décadas debido a la desmedida expansión del sistema financiero internacional, que ha sumado un factor de gran importancia a la inestabilidad de la economía internacional y ha desembocado en la profunda crisis actual. Esta inestabilidad global produce a su vez marcadas oscilaciones en los niveles de empleo y de salarios, con el consiguiente efecto negativo en las condiciones de vida de la mayor parte de la población, especialmente la de los estratos de menores ingresos, lo que en Chile es otro factor decisivo de pobreza y desigualdad.

Por último, la nueva política macroeconómica debe privilegiar no solo un crecimiento razonable y sostenido, sino también orientar los incentivos y los precios básicos a fin de promover la convergencia productiva. Deberá aplicarse una política centrada no solo en los equilibrios básicos y el crecimiento en sí, sino también en enfrentar la vulnerabilidad de este ante los cambios en la economía internacional. De esta manera, se evitarían la subutilización de la capacidad productiva y los efectos negativos de las oscilaciones de la actividad económica en la productividad, que afectan de distinta forma a los diferentes estratos de la producción, así como al empleo y al ingreso de los trabajadores que laboran en ellos.

\section{La cohesión social}

En la actualidad, los problemas relacionados con la desigualdad, la integración comunitaria, la vida familiar, la protección del medio ambiente, la seguridad y la calidad de vida ocupan un lugar cada vez más destacado (Machinea y Uthoff, 2004). Las falencias del modelo imperante para hacer frente a estas nuevas demandas resultan evidentes. En este contexto, cabe citar el ejemplo de la Unión Europea, donde la cohesión social radica básicamente en un Estado que garantiza a sus ciudadanos igual acceso a ciertos derechos fundamentales y no confía ingenuamente en que el mercado traerá los resultados deseados en forma automática.

La aplicación de la estrategia de desarrollo inclusivo propuesta, mediante la acción recíproca de los distintos aspectos que la componen (convergencia productiva, cambios institucionales y crecimiento con equidad), debería traducirse en el fortalecimiento de la cohesión social.

Es un hecho ampliamente reconocido que en cualquier país el empleo es una de las principales vías de inclusión social. Según la calidad del trabajo, el grado de inclusión de los diferentes sectores sociales será mayor o menor y el tipo de inclusión más o menos adecuado. Es por ello que las políticas de generación de empleo en beneficio de los sectores de menor productividad, en especial de las personas desempleadas y que pertenecen a 
la población pobre, constituyen el principal instrumento de las estrategias de inclusión social, elemento fundamental para el afianzamiento de la democracia.

En definitiva, aun a riesgo de caer en la repetición, una estrategia de integración social mediante la creación de empleos de calidad requiere un fuerte y sostenido apoyo de recursos para promover la convergencia productiva durante un período prolongado, mientras que las decisiones sobre la magnitud y aplicación de esos recursos deberían adoptarse por la vía del diálogo social. Una orientación de este tipo necesita un pacto social que incluya acuerdos para aumentar los ingresos fiscales y utilizar el ahorro nacional acumulado, de modo que la estrategia de desarrollo inclusivo tenga la necesaria sustentabilidad financiera para asegurar la cohesión social a mediano y largo plazos.

\section{Bibliografía}

Assael, H. (1998), "La búsqueda de la equidad", Revista de la CEPAL, número extraordinario (LC/G.2037-P), Santiago de Chile, Comisión Económica para América Latina y el Caribe (CEPAL), octubre.

Banco Central de Chile (2003), Cuentas nacionales de Chile: compilación de referencia 2003 Matriz de insumo producto de la economía chilena, Santiago de Chile.

Bravo, D. y D. Contreras (1999), La distribución del ingreso en Chile 1990-1996: análisis del impacto del mercado del trabajo y las políticas sociales, Santiago de Chile, Departamento de Economía, Facultad de Ciencias Económicas y Administrativas, Universidad de Chile.

Calderón, Fernando (2008), "Una inflexión histórica. Cambio político y situación socioinstitucional en América Latina", Revista de la CEPAL, $\mathrm{N}^{\circ} 96$ (LC/G.2396-P), Santiago de Chile, diciembre.

CEPAL (Comisión Económica para América Latina y el Caribe) (2008), La transformación productiva 20 años después. Viejos problemas, nuevas oportunidades (LC/G.2367(SES.32/3)), Santiago de Chile, mayo.

(1964), La mano de obra y el desarrollo económico de América Latina en los últimos años (E/CN.12/L.1), Santiago de Chile.

Cimoli, M. (comp.) (2005), Heterogeneidad estructural, asimetrías tecnológicas y crecimiento en América Latina (LC/W.35), Santiago de Chile, Comisión Económica para América Latina y el Caribe (CEPAL).

Cimoli, M., A. Primi y M. Pugno (2006), "Un modelo de bajo crecimiento: la informalidad como restricción estructural", Revista de la CEPAL, N ${ }^{\circ} 88$ (LC/G.2289-P), Santiago de Chile, abril.

Comisión de las Comunidades Europeas (1993), Crecimiento, competitividad, empleo. Retos y pistas para entrar en el siglo XXI, Luxemburgo.

Contreras, D. (1998), "Distribución del ingreso en Chile. Nueve hechos y algunos mitos", resumen del proyecto "La distribución del ingreso en Chile 1990-1996: análisis del impacto del mercado del trabajo y las "políticas sociales"”, Santiago de Chile, Fondo de Políticas Públicas.

EuRostat (Oficina de Estadística de las Comunidades Europeas) (1998), Task Force Recommendations (EP/SEP/5/98), Luxemburgo.

Feres, M.E. y R. Infante (2007), "Chile: las relaciones laborales del futuro", Colección Ideas, Santiago de Chile, Ediciones Fundación Chile 21.

Ffrench-Davis, R. (2003), Entre el neoliberalismo y el crecimiento con equidad: tres décadas de política económica en Chile, Santiago de Chile, Lom Ediciones.

Guardia, A. (2007), "Lineamientos de una estrategia exportadora para el aprovechamiento de los acuerdos comerciales y las cadenas productivas", Perspectivas económicas para el Chile del Bicentenario: desafíos y oportunidades, M. Jélvez (comp.), Santiago de Chile, Centro de Estudios para el Desarrollo (CED)/Programa de las Naciones Unidas para el Desarrollo (PNUD).
INE (Instituto Nacional de Estadísticas) (1998), Encuesta de presupuestos familiares 1996/1997, Santiago de Chile.

Infante, R. (2008), El sector de empresas pequeñas y medianas: lecciones de la experiencia de la Unión Europea y politicas de homogeneización productiva con generación de empleo (LC/G.2895-P), Santiago de Chile, Comisión Económica para América Latina y el Caribe (CEPAL). Publicación de las Naciones Unidas, $\mathrm{N}^{\mathrm{o}}$ de venta: S.08.II.G.31.

(2007a), "Una política de distribución de ingresos desde la perspectiva de la heterogeneidad estructural", Perspectivas económicas para el Chile del Bicentenario: desafíos y oportunidades, M. Jélvez (comp.), Santiago de Chile, Centro de Estudios para el Desarrollo (CED)/Programa de las Naciones Unidas para el Desarrollo (PNUD).

(comp.) (2007b), Empleo, trabajo y protección: retos para un mercado laboral incluyente, Santiago de Chile, Ediciones Fundación Chile 21.

(comp.) (2006), Chile: transformar las necesidades sociales en nuevas oportunidades de empleo, Santiago de Chile, Ediciones Fundación Chile 21.

(1981), "Heterogeneidad estructural, empleo y distribución del ingreso", El trimestre económico, vol. 48(2), № 190, México, D.F., Fondo de Cultura Económica, abril-junio.

Infante, R., S. Molina y O. Sunkel (2007), "Hacia una estrategia de desarrollo incluyente", Proyecto Desarrollo incluyente, Santiago de Chile, Fundación Chile 21.

Lagos E., R. (2008), El futuro comienza hoy, Santiago de Chile, Editorial Copa Rota.

Lagos M., C. (2008), "Desarrollo inclusivo. Matriz de insumo-producto sectorial en una economía heterogénea: Chile 2003", Proyecto Desarrollo incluyente, Santiago de Chile, Fundación Chile 21.

Machinea, J.L. y A. Uthoff (2004), "La importancia de la cohesión social en la inserción internacional de América Latina", Documentos de proyectos, $\mathrm{N}^{\circ} 9$ (LC/W.29/Rev.1), Santiago de Chile, Comisión Económica para América Latina y el Caribe (CEPAL).

MIDEPLAN (Ministerio de Planificación) (2007), "La situación de la pobreza en Chile", serie Análisis de resultados de la Encuesta CASEN, $\mathrm{N}^{\circ} 2$, Santiago de Chile.

(2006a), "Distribución del ingreso e impacto distributivo del gasto social", serie Análisis de resultados de la Encuesta CASEN, $\mathrm{N}^{\circ}$ 2, Santiago de Chile.

(2006b), "Metodología de valorización de los subsidios en salud, educación y monetarios", Casen 2006, Santiago de Chile.

(varios años), Encuesta de Caracterización Económica: CASEN 1990-2006, Santiago de Chile.

Muñoz, O. (2008), "El cluster del salmón: ¿un caso de desarrollo incluyente?", Proyecto Desarrollo incluyente, Santiago de Chile, Fundación Chile 21.

(2007), El modelo económico de la Concertación, 19902005. ¿Reformas o cambio?, Santiago de Chile, Editorial Catalonia. 
Pinto, A. (1970), "Naturaleza e implicaciones de la "heterogeneidad estructural' de América Latina", El trimestre económico, vol. 37(1), $\mathrm{N}^{\circ} 145$, México, D.F., Fondo de Cultura Económica.

Pinto, A. y A. Di Filippo (1982), "Desarrollo y pobreza en América Latina: un enfoque histórico estructural", Pobreza, necesidades básicas y desarrollo, R. Franco (comp.), Santiago de Chile, Comisión Económica para América Latina y el Caribe (CEPAL)/ Instituto Latinoamericano y del Caribe de Planificación Económica y Social (ILPES)/Fondo de las Naciones Unidas para la Infancia (UNICEF).

- (1974), "Notas sobre la estrategia de la distribución y la redistribución del ingreso en América Latina", Distribución del ingreso, A. Foxley (comp.), México, D.F., Fondo de Cultura Económica.

Román, E. (2008), "Estrategias, institucionalidad y políticas públicas para un desarrollo inclusivo", Proyecto Desarrollo incluyente, Santiago de Chile, Fundación Chile 21.

Rupfer, D. y F. Rocha (2005), "Productividad y heterogeneidad estructural en la industria brasileña", Heterogeneidad estructural, asimetrías tecnológicas y crecimiento en América Latina, M. Cimoli (comp.), Santiago de Chile, Comisión Económica para América Latina y el Caribe (CEPAL).

Salter, W.E.G. (1966), Productivity and Technical Change, Cambridge, Cambridge University Press.

Servicio de Impuestos Internos (2000), Ventas por sector económico y tamaño, Santiago de Chile, Servicio de Impuestos Internos.

Slavinsky, Z. (1964), "Anexo estadístico", La mano de obra y el desarrollo económico de América Latina en los últimos años (E/CN.12/L.1), Santiago de Chile, Comisión Económica para América Latina y el Caribe (CEPAL).

Solimano, A. y M. Pollak (2006), La mesa coja: prosperidad y desigualdad en el Chile democrático, Santiago de Chile, Ediciones LOM.

Souza, P. y V. Tokman (1979), "Distribución del ingreso, pobreza y empleo en áreas urbanas", Distribución del ingreso en
América Latina, O. Muñoz (comp.), Santiago de Chile, Consejo Latinoamericano de Ciencias Sociales (CLACSO).

Sunkel, O. (2008), "La precaria sustentabilidad de la democracia en América Latina", Cuadernos del Cendes, vol. 25, Nº 68, Caracas, Centro de Estudios del Desarrollo (CENDES).

(2006a), "Un ensayo sobre los grandes giros de la política económica chilena y sus principales legados", Brasil y Chile, una mirada hacia América Latina, en R, Bielschowsky y otros, Santiago de Chile, Instituto de Estudios Internacionales, Universidad de Chile/Embajada del Brasil.

(2006b), "La distribución del ingreso en Chile", Revista Foro 21, año 6, N ${ }^{\circ}$ 58, Santiago de Chile, Fundación Chile 21.

(2006c), "En busca del desarrollo perdido", Problemas del desarrollo. Revista Latinoamericana de Economía, vol. 37, No 147, México, D.F., Instituto de Investigaciones Económicas, Universidad Nacional Autónoma de México, octubre-diciembre.

(1978), "Dependencia y la heterogeneidad estructural", $E l$ trimestre económico, vol. 45(1), No 177, México, D.F., Fondo de Cultura Económica, enero-marzo.

(1971), "Capitalismo transnacional y desintegración nacional en América Latina”, El trimestre económico, vol. 38, № 150, México, D.F., abril-junio.

Sunkel, O. y R. Infante (2006), "Hacia un crecimiento incluyente", Foro Chile 21, año 6, $\mathrm{N}^{\circ}$ 61, Santiago de Chile, Ediciones Fundación Chile 21.

Tokman, V. (2004), Una voz en el camino. Empleo y equidad en América Latina: 40 años de búsqueda, Santiago de Chile, Fondo de Cultura Económica.

(1982), "Desarrollo desigual y absorción del empleo: América Latina 1950-80", Revista de la CEPAL, N 17 (E/CEPAL/G.1205), Santiago de Chile, Comisión Económica para América Latina y el Caribe (CEPAL).

Unión Europea (1997), Cumbre Extraordinaria del Empleo, Luxemburgo. 